\title{
Electrochemical corrosion of magnetron sputtered WTiN-coated mild steels in a chloride medium
}

\author{
Valéria A. Alves ${ }^{\mathrm{a}, \mathrm{b}}$, Christopher M.A. Brett ${ }^{\mathrm{a}, *}$, Albano Cavaleiro $^{\mathrm{c}}$

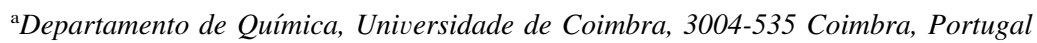 \\ bepartamento de Ciências Básicas, Faculdade Federal de Odontologia de Diamantina, Rua da Glória 187, 39100-000 Diamantina, \\ Minas Gerais, Brazil \\ ${ }^{\mathrm{c}}$ Departamento de Engenharia Mecânica, Universidade de Coimbra, 3030-201 Coimbra, Portugal
}

Received 24 April 2002; accepted in revised form 22 July 2002

\begin{abstract}
The electrochemical corrosion behaviour of WTiN coatings, of composition $\mathrm{W} 31$, Ti 28 and $\mathrm{N} 40$ at.\% sputtered on carbon steel, chromium steel and high speed steel (HSS) has been investigated and the effect of the steel heat treatment on the steel/ WTiN system performance explored. Open circuit potential measurements, polarisation curves and electrochemical impedance spectroscopy were used, together with X-ray diffraction and scanning electron microscopy to characterise the corroded and uncorroded coating/substrate systems. It was found that the influence of the substrate on corrosion resistance follows the order Carbon Steel $<$ HSS $<$ Chromium Steel. The best performance of the chromium steel/WTiN system can be associated with the higher compactness of the protective coating, since there is strong evidence that it is inert so that electrolyte penetration through the coating defects and pores is responsible for the initiation of substrate corrosion. Heat treatment of the substrate has some influence on the corrosion of the HSS/coating system, suggesting that there may be one ideal steel treatment temperature for which the coating adhesion is higher.
\end{abstract}

(C) 2002 Elsevier Science B.V. All rights reserved.

Keywords: Corrosion; Coated steels; Sputtering; Carbon steel; High speed steel; Chromium steel

\section{Introduction}

Thin film coatings of one or more metals and incorporating nitrogen, deposited by physical vapour deposition, generally show increased wear and corrosion resistance, with respect to the corresponding non-nitrogen-containing films [1]. Most research on the corrosion resistance of film/substrate systems has involved TiN coatings [2,3] as well as Ti/TiN multilayer coated steels [4].

Sputtered films of WN have a very high hardness [5] and consequently high wear resistance. Recently, the incorporation of Ti in these WN sputtered films showed an increase in oxidation resistance-protection against high temperature oxidation is a key feature for the

\footnotetext{
*Corresponding author. Tel./fax: +351-239-835295.
}

E-mail address: brett@ci.uc.pt (C.M. Brett). increase of service life of cutting tools [6,7]. In view of these promising properties, the electrochemical corrosion of WTiN and other W-based coatings sputtered on AISI M2 high speed steel (HSS), a steel widely used for fabrication of tools, was investigated in $\mathrm{Al}^{-}$-containing aggressive aqueous medium [8-11]. A recent publication [12] discusses the performance of these hard coatings with respect to the electrochemical corrosion resistance of HSS. Details of the corrosion process, as well as new considerations concerning the corrosion mechanism proposed in Ref. [10] are discussed.

It was found that films of $\mathrm{CrN}$ led to a significant improvement of the wear and corrosion resistance of HSS, particularly for less rough substrates [13]. It was also verified that the application of TiN coatings on less rough substrates leads to a higher corrosion resistance [14], ascribed to a lower density of coating defects, and 
CrN-coated steel exhibited better corrosion-properties than TiN coated steel. In Ref. [11] films of WTiN were sputter-deposited on HSS substrates using various different surface preparation and deposition conditions which influenced the surface roughness and could have effects on the film structure. Image analysis of pits formed in the films after subjecting them to testing in salt spray test chambers demonstrated in this case also the importance of both substrate roughness and coating deposition conditions in influencing corrosion resistance, attributed to alterations in coating structure.

A systematic study of the influence of the substrate on the corrosion and corrosion mechanism of W-based coatings has not yet been performed. The purpose of this work was to study the electrochemical corrosion behaviour of WTiN coatings sputtered on three different types of steel substrate: carbon steel, chromium steel and HSS and to ascertain if the substrate influences defects in the coating and thence electrolyte penetration. The effect of the steel heat treatment on the steel/WTiN system performance is also explored. The corrosion behaviour of these steel substrates in the same medium has been previously studied [15-17], and will be compared with the behaviour of the respective WTiN coated steels.

\section{Experimental}

\subsection{Sputtering deposition conditions for WTiN films on steel substrates}

Three types of steel were used as substrates for the deposition of the WTiN: carbon steel (1015 AISI), chromium steel $\left(\right.$ CALMAX $\left.^{\circledR}\right)$ and HSS (M2 AISI) $[16,17]$, whose chemical compositions and sample areas are given in Table 1. Prior to coating, a heat treatment was performed with tempering temperatures of $450{ }^{\circ} \mathrm{C}$ for chromium steel and 550 or $650{ }^{\circ} \mathrm{C}$ for HSS, see Refs. [16,17] for the detailed procedure. The as-received steels were also coated.

After polishing to a mirror finish with diamond paste of $6 \mu \mathrm{m}$ particle size the samples were sputter-coated on one face in a Hartec d.c. magnetron sputtering apparatus. The surface was cleaned by electron heating and argon ion etching, and the deposition was done from a W $+20 \mathrm{wt} . \%$ Ti target at a power density of 11 $\mathrm{W} \mathrm{cm}{ }^{-2}$ and a negative substrate bias of $70 \mathrm{~V}$; the substrate temperature was kept at $450{ }^{\circ} \mathrm{C}$. The total gas
Table 2

Chemical composition by EPMA in at.\% of the WTiN sputtered coatings

\begin{tabular}{llll}
\hline System type & W & Ti & N \\
\hline Carbon steel/WTiN & 31.6 & 29.0 & 39.4 \\
Chromium steel AR/WTiN & 31.9 & 28.5 & 39.9 \\
Chromium steel $\left(450{ }^{\circ} \mathrm{C}\right) /$ WTiN & 32.2 & 27.6 & 40.2 \\
HSS AR/WTiN & 31.5 & 29.1 & 39.4 \\
HSS $\left(550^{\circ} \mathrm{C}\right) / \mathrm{WTiN}$ & 29.4 & 28.7 & 41.9 \\
$\mathrm{HSS}\left(650^{\circ} \mathrm{C}\right) / \mathrm{WTiN}$ & 31.0 & 28.5 & 40.5 \\
\hline
\end{tabular}

$\mathrm{AR}$, as-received; the values in brackets refer to the steel tempering temperature.

pressure during deposition was $0.3 \mathrm{~Pa}$; the gas was a mixture of nitrogen and argon with a partial pressure ratio of 1 to 3 . Each sputtering deposition led to six deposited samples with coating thickness of $\sim 4 \mu \mathrm{m}$. The exact chemical compositions of the different steel/ WTiN coated systems as determined by electron probe microanalysis (EPMA) are shown in Table 2. These confirm that only small variations in composition occur due to changes in the relative deposition rate of the elements that can be ascribed mainly to differences in substrate microstructure and roughness after etching, as well as in film structure and morphology [11].

Electrodes were prepared from the coated samples by attaching a copper wire to the rear face with silver epoxy and covering the whole assembly with epoxy resin and varnish, leaving just the WTiN coated face exposed.

\subsection{Solutions, cell and instrumentation}

All electrochemical measurements were carried out in $0.1 \mathrm{M} \mathrm{KCl}$ aqueous solution, prepared using analytical grade reagent and ultrapure water (Millipore Milli-Q, resistivity $>18 \mathrm{M} \Omega \mathrm{cm}$ ). The solutions were not deaerated and the measurements were made at $25 \pm 1{ }^{\circ} \mathrm{C}$.

A three-electrode cell, containing $100 \mathrm{~cm}^{3}$ of solution, a Pt foil auxiliary electrode (surface area $3 \mathrm{~cm}^{2}$ ) and a saturated calomel reference electrode was employed, controlled by an EG\&G PAR273A potentiostat with M352 Corrosion Analysis Software or, for impedance experiments, by a Solartron 1250 frequency response analyser with a model 1286 electrochemical interface, using a $5 \mathrm{mV}$ r.m.s. perturbation from $10 \mathrm{kHz}$ down to $25 \mathrm{mHz}$. Experiments were controlled with ZPlot soft-

Table 1

Chemical composition in wt.\% and area of the steel samples

\begin{tabular}{lcccccccc}
\hline Type of steel & W & Mo & Cr & V & C & Mn & Si & Area/cm \\
\hline HSS M2 (AISI) & 6.4 & 5.0 & 4.2 & 1.9 & 0.9 & $<0.4$ & $<0.4$ & 1.8 \\
Chromium steel CALMAX & - & 0.5 & 4.5 & 0.2 & 0.6 & 0.8 & $<0.4$ & 2.0 \\
Carbon steel 1015 (AISI) & - & - & - & - & 0.17 & $<1.0$ & - & 3.1 \\
\hline
\end{tabular}




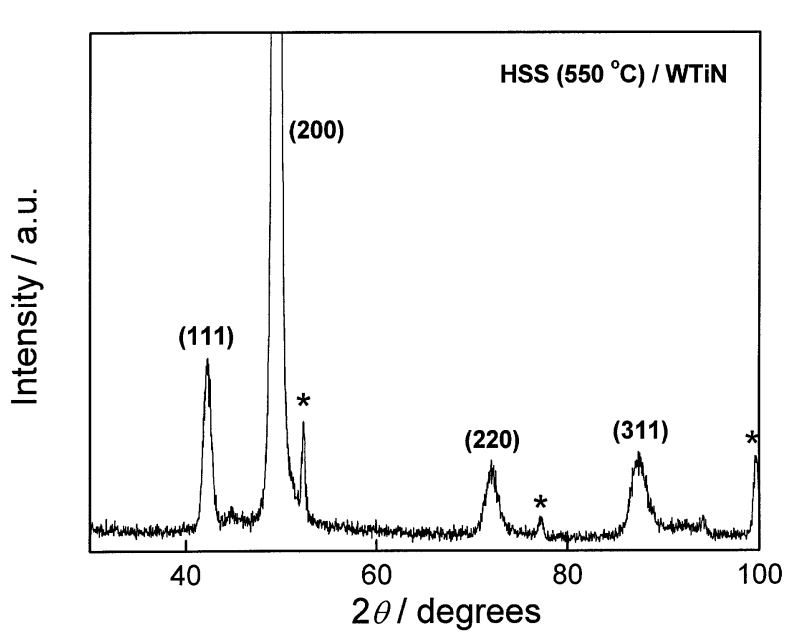

Fig. 1. X-ray diffraction spectrum of WTiN sputtered film on HSS heat-treated at $550{ }^{\circ} \mathrm{C}$ before corrosion. The peaks marked with $*$ are due to the iron matrix (steel substrate).

ware and fitting was performed with ZSim CNLS software.

Scanning electron microscopy (SEM) was carried out on a Jeol T330 SEM equipped with a Tracor Northern microanalysis accessory. X-ray diffraction analysis was done using a Philips, PW3040/00 X-PERTH diffractometer, with a Co tube operated at $40 \mathrm{kV}$ and $35 \mathrm{~mA}$.

\section{Results and discussion}

\subsection{X-ray diffraction analysis of the WTiN coated steels}

The structure of the WTiN coated steel systems was analysed by X-ray diffraction. Fig. 1 shows a representative diffractogram of a steel/WTiN coated system. For all systems it is still possible to observe the presence of diffraction peaks of the substrate, marked with an asterisk, although these peaks have a very low intensity compared to those from the WTiN coating. Independent of the steel/coating system, the WTiN films have a face centred cubic structure, which can be identified as a mixed nitride phase of $\mathrm{W}_{2} \mathrm{~N}$ and TiN [6,7]. These phases are isomorphous and completely miscible, since they have approximately the same interplanar distances [18]. This means that the Ti atoms can substitute those of $\mathrm{W}$ in the $\mathrm{W}_{2} \mathrm{~N}$ lattice and vice versa. Details concerning the morphology of WTiN produced by sputtering can be found in Ref. [19]. The coatings show a typical very compact type $\mathrm{T}$ cross-section morphology, according to Thornton's structure zone model [20], in agreement with other research. No evident differences were found between the cross-section morphologies of films deposited on the various substrates.

\subsection{Open circuit potential as a function of time}

The corrosion potential, $E_{\text {cor }}$, at open circuit as a function of immersion time for the different WTiN coated steel samples is shown in Fig. 2. For comparison, the corresponding plots for the uncoated steel substrates are also shown. From these plots it can be seen that $E_{\text {cor }}$ values of WTiN coated steels are always more positive than those of the uncoated steels, suggesting that in all cases the coating provides substrate protection against pitting corrosion.

The $E_{\text {cor }}$ values of the coated steels become more negative with immersion time, tending to those of the respective substrates, which are reached after periods approaching $24 \mathrm{~h}$. They suggest that the function of the WTiN coating is primarily to protect the steel from
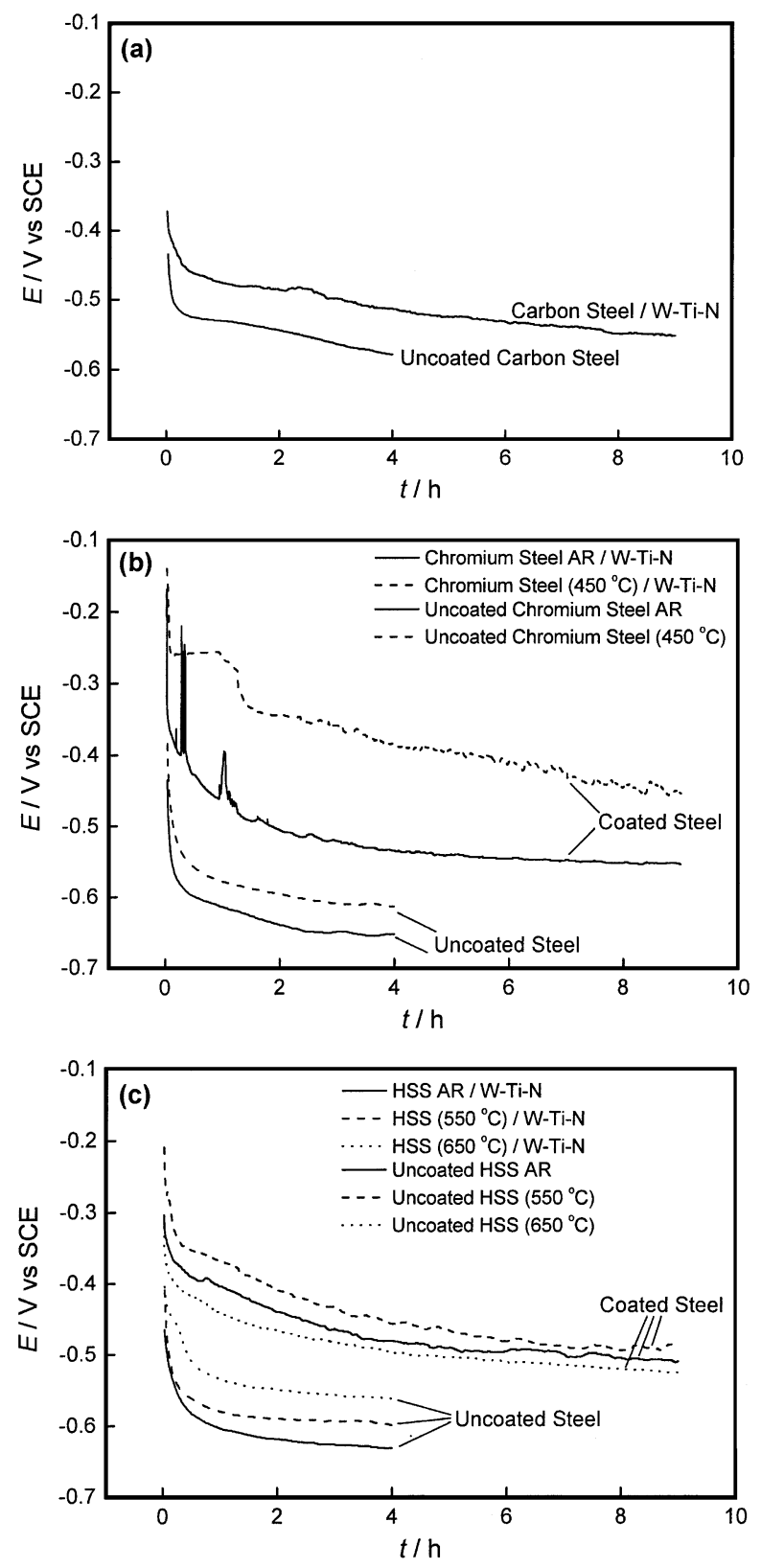

Fig. 2. Plot of open circuit corrosion potential, $E_{\text {cor }}$ vs. time for the various steel/WTiN coated systems, as well as for the uncoated steels, in $0.1 \mathrm{M} \mathrm{KCl}$ solution. (a) carbon steel; (b) chromium steel; (c) HSS. 
Table 3

Values of $E_{\text {cor }}$ (vs. SCE) of WTiN coated steels from open circuit potential measurements as a function of immersion time

\begin{tabular}{llll}
\hline $\begin{array}{l}\text { Substrate for WtiN } \\
\text { coated system }\end{array}$ & \multicolumn{3}{l}{$-E_{\text {cor }} / \mathrm{V}$ vs. SCE } \\
\cline { 2 - 4 } & $10 \mathrm{~min}$ & $1 \mathrm{~h}$ & $4 \mathrm{~h}$ \\
\hline Carbon steel & 0.431 & 0.476 & 0.513 \\
Chromium steel AR & 0.390 & 0.414 & 0.535 \\
Chromium steel $\left(450{ }^{\circ} \mathrm{C}\right)$ & 0.259 & 0.267 & 0.385 \\
HSS AR & 0.367 & 0.404 & 0.481 \\
$\mathrm{HSS}\left(550^{\circ} \mathrm{C}\right)$ & 0.322 & 0.369 & 0.457 \\
$\mathrm{HSS}\left(650{ }^{\circ} \mathrm{C}\right)$ & 0.396 & 0.441 & 0.497 \\
\hline
\end{tabular}

being attacked by chloride ions, since if the coatings were also corroded, the $E_{\text {cor }}$ values would be independent of the substrate type. The influence of composition and heat treatment for chromium steel and HSS can be seen from the values in Table 3 after 10 min, 1 and $4 \mathrm{~h}$ immersion. Table 3 clearly shows that, besides the substrate composition, the heat treatment also influences the corrosion resistance of the substrate/coating system. Previous work on uncoated steels has demonstrated that a heat treatment increases the corrosion resistance of HSS [16,17] and of chromium steel [17]. It is therefore surprising that HSS tempered at $650{ }^{\circ} \mathrm{C}$ shows more negative $E_{\text {cor }}$ values than those of as-received HSS and it is deduced that $550{ }^{\circ} \mathrm{C}$ is the better tempering temperature. The relatively bad performance of the system HSS tempered at $650{ }^{\circ} \mathrm{C} /$ coating was not expected; it must be associated with a lower chemical and/or physical interaction between this steel sample and the coating. A possible explanation for its worse performance can be a higher substrate surface roughness resulting from the cleaning by ion bombardment before sputtering deposition of the coating. In accordance with this hypothesis, Lee et al. [13] showed that surfaces with different chemical or physical structures seem also to lead to coatings with different properties.

Fig. 3 shows the open circuit potential values at 10 min immersion for the different samples of each type of system, used in the different electrochemical measurements; the error bars result from three measurements. From this plot, it is possible to have a more accurate idea about the initial corrosion resistance of the coated substrate systems. The corrosion resistance of the system chromium steel/WTiN coating is higher, followed by that of HSS/WTiN and carbon steel/WTiN, respectively.

Visual and SEM observation of the coated steels during the experiments shows that corrosion is essentially localised in all types of sample, and the pits appear during the first half-hour after immersion. In agreement with previous studies [8-12], in which films of different compositions ( $\mathrm{W}-\mathrm{M}-\mathrm{N}$, where $\mathrm{M}=\mathrm{Ni}, \mathrm{Ti}, \mathrm{Al}$ ) were sputtered onto HSS substrates, these measurements sug- gest that corrosion occurs as a consequence of electrolyte penetration through defects in the WTiN films.

\subsection{Polarisation curves}

Polarisation curves were obtained for all coated steel samples, in the potential range -250 to $+250 \mathrm{mV}$ from the open circuit potential. Fig. $4 a-c$ show all curves for all steels at $10 \mathrm{~min}, 1$ and $4 \mathrm{~h}$ immersion time, respectively. Curve fitting and Tafel analysis were carried out using the M352 ParCalc routine to obtain values of corrosion currents and corrosion potentials, $I_{\text {cor }}$ and $E_{\text {cor }}$, see Table 4 .

The carbon steel/WTiN system exhibited the highest values of corrosion currents (at $10 \mathrm{~min}$ and $1 \mathrm{~h}$ immersion) and the most negative values of corrosion potential (at $10 \mathrm{~min}$ and $4 \mathrm{~h}$ immersion), in agreement with the $E_{\text {cor }}$ measurements at open circuit. This further corroborates the fact that the system response concerning corrosion is mainly related to the substrate properties.

Chromium steel as-received showed the lowest values of $I_{\text {cor }}$, followed by chromium steel tempered at $450{ }^{\circ} \mathrm{C}$ and HSS as-received and tempered at $550{ }^{\circ} \mathrm{C}$, which had similar $I_{\text {cor }}$ values up to $1 \mathrm{~h}$ immersion. Again, HSS tempered at $650{ }^{\circ} \mathrm{C}$ had the lowest corrosion resistance (higher $I_{\text {cor }}$ and more negative $E_{\text {cor }}$ ) when compared with all the other coated steels, except for coated carbon steel.

The coated steel samples, as well as having a lower rate of corrosion than the respective substrates at the same immersion times, do not show a significant shift of $E_{\text {cor }}$ in the negative direction after recording of the polarisation curves.

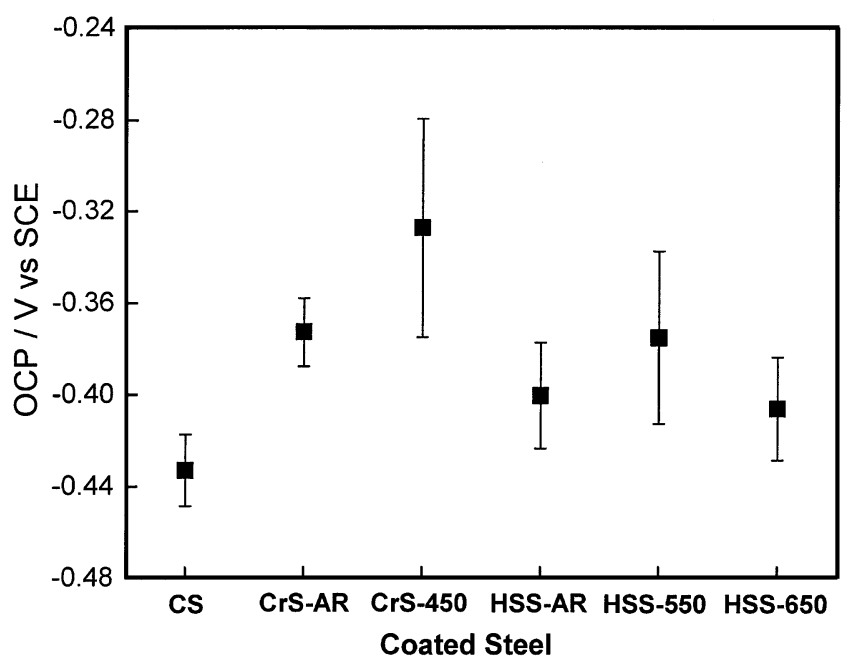

Fig. 3. Values of open circuit corrosion potential, $E_{\text {cor }}$, at $10 \mathrm{~min}$ immersion, for various samples of each steel/WTiN coated system in $0.1 \mathrm{M} \mathrm{KCl}$ solution. The substrates are: CS, Carbon steel; CrS-AR, chromium steel as-received; CrS-450, chromium steel tempered at 450 ${ }^{\circ} \mathrm{C}$; HSS-AR, HSS as-received; HSS-550, HSS tempered at $550{ }^{\circ} \mathrm{C}$; HSS-650, HSS tempered at $650{ }^{\circ} \mathrm{C}$. 

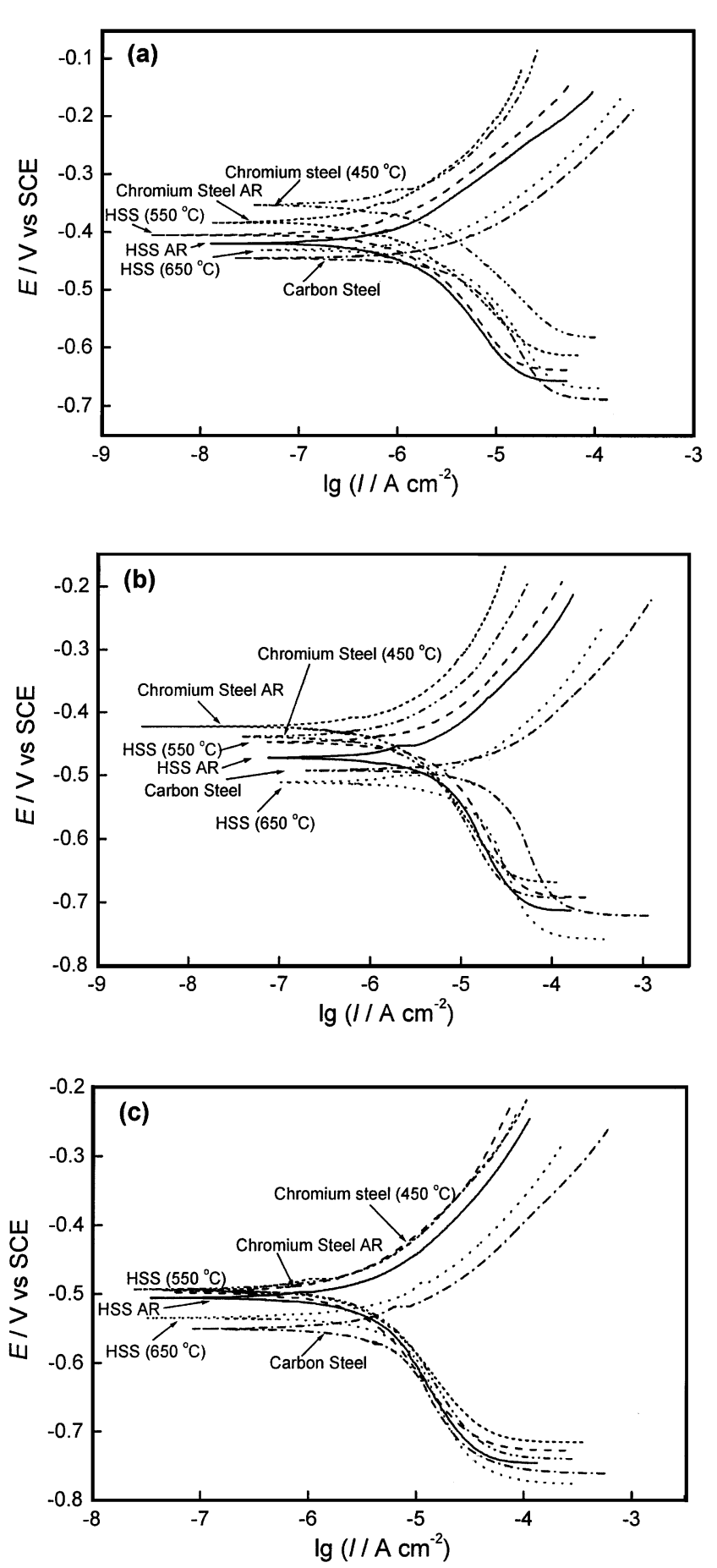

Fig. 4. Tafel plots for the various steel/WTiN coated systems after immersion in $0.1 \mathrm{M} \mathrm{KCl}$ solution for (a) $10 \mathrm{~min}$; (b) $1 \mathrm{~h}$; and (c) 4 h. Scan rate, $2.5 \mathrm{mV} \mathrm{s}^{-1}$.

The fact that the cathodic part of the polarisation curves is very similar after several hours immersion (Fig. 4c) is evidence that the anodic reaction is ratedetermining. This is as expected if the substrate is undergoing corrosion, and has been previously demonstrated [15-17]. From the ratio between the corrosion currents of the uncoated steels [17] and those of the
Table 4

Corrosion parameters obtained from analysis of the polarisation curves of WTiN coated steels for different immersion times

\begin{tabular}{|c|c|c|c|c|c|c|}
\hline \multirow{2}{*}{$\begin{array}{l}\text { Substrate for WTiN } \\
\text { coated system }\end{array}$} & \multicolumn{3}{|c|}{$I_{\text {cor }} / \mu \mathrm{A} \mathrm{cm}^{-2}$} & \multicolumn{3}{|c|}{$-E_{\text {cor }} / \mathrm{V}$ vs. SCE } \\
\hline & $10 \mathrm{~min}$ & $1 \mathrm{~h}$ & $4 \mathrm{~h}$ & $10 \min$ & $1 \mathrm{~h}$ & $4 \mathrm{~h}$ \\
\hline Carbon steel & 5.6 & 12.6 & 12.4 & 0.45 & 0.49 & 0.55 \\
\hline Chromium steel AR & 0.9 & 2.8 & 4.3 & 0.38 & 0.42 & 0.49 \\
\hline Chromium steel $\left(450{ }^{\circ} \mathrm{C}\right)$ & 1.3 & 4.4 & 5.8 & 0.35 & 0.44 & 0.49 \\
\hline HSS AR & 1.3 & 4.2 & 8.5 & 0.42 & 0.47 & 0.51 \\
\hline $\operatorname{HSS}\left(550{ }^{\circ} \mathrm{C}\right)$ & 1.1 & 4.7 & 5.2 & 0.41 & 0.45 & 0.50 \\
\hline $\operatorname{HSS}\left(650^{\circ} \mathrm{C}\right)$ & 4.9 & 9.3 & 14.0 & 0.43 & 0.51 & 0.53 \\
\hline
\end{tabular}

coated steels, it was found that the WTiN film reduced the anodic current density up to 30 times for as-received chromium steel at short immersion times, see the example in Fig. 5. The lowest ratios, of approximately 2, were obtained for carbon steel and HSS tempered at $650{ }^{\circ} \mathrm{C}$.

\subsection{Electrochemical impedance spectroscopy}

Impedance spectra were recorded at an applied potential corresponding to the open circuit potential for all WTiN coated steel samples after $10 \mathrm{~min}, 1$ and $4 \mathrm{~h}$ immersion. The general shape of the spectra is similar, as well as changes in spectra as a function of the immersion time, see Fig. 6 .

The spectra obtained can be compared with those of the uncoated steel $[16,17]$. They present two time constants, independent of the immersion time, while those of the respective uncoated steels had only one, with the exception of carbon steel and chromium steel AR (at longer immersion times). This behaviour reflects the more complex nature of the substrate/WTiN system. Secondly, the much higher impedance of the substrate/ WTiN system than that of the uncoated steel, even after

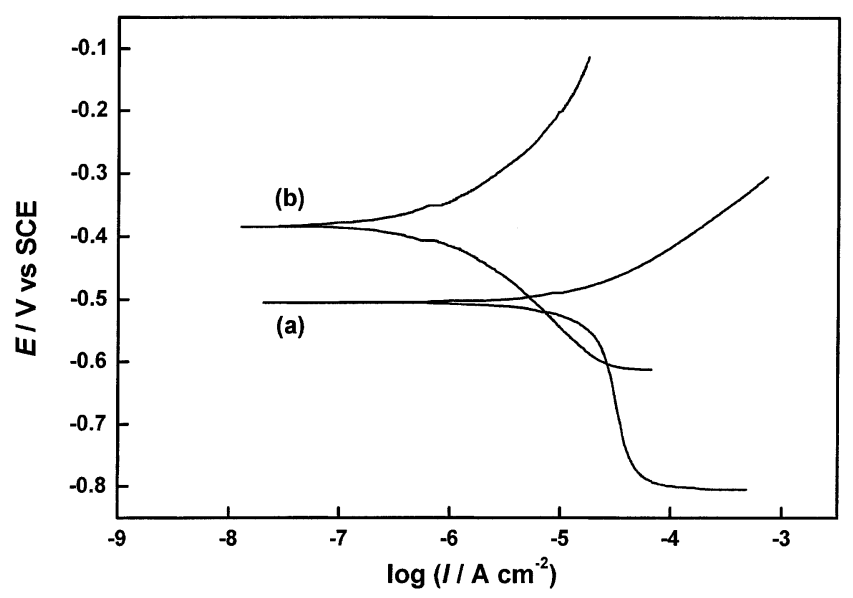

Fig. 5. Tafel plots for (a) uncoated chromium steel AR and (b) chromium steel AR/WTiN coated system after $10 \mathrm{~min}$ immersion in 0.1 $\mathrm{M} \mathrm{KCl}$ solution. Scan rate, $2.5 \mathrm{mV} \mathrm{s}^{-1}$. 

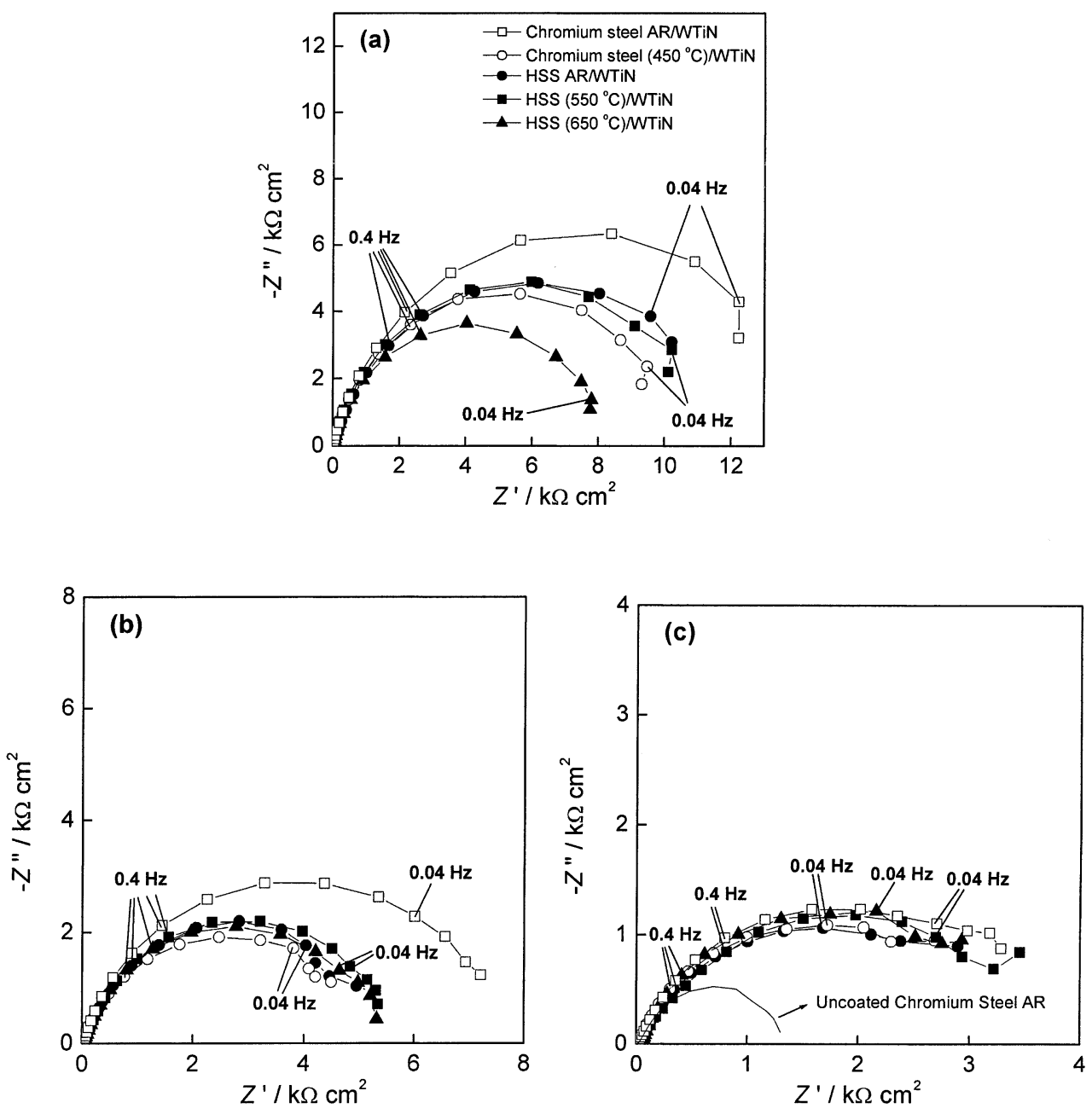

Fig. 6. Evolution with time of the complex plane impedance spectra at the open-circuit potential for the WTiN coated systems in $0.1 \mathrm{M}$ KCl solution: (a) $10 \mathrm{~min}$; (b) $1 \mathrm{~h}$; (c) $4 \mathrm{~h}$ immersion.

$4 \mathrm{~h}$ immersion (Fig. 6c), reflects the higher corrosion resistance of the substrate/WTiN system.

Nevertheless, there is a systematic decrease of the coated system impedance with immersion time, due to electrolyte penetration through the coating defects or pores and the consequent increase of substrate corrosion. This is in agreement with similar systems previously studied: HSS/WNiN [9] or HSS/WMN (where $\mathrm{M}=\mathrm{Ni}$, $\mathrm{Ti}, \mathrm{Al})$ [10], and with the increase in $I_{\text {cor }}$ values with immersion time (Table 4).

The electrical equivalent circuit drawn in Fig. 7a was used to fit the experimental data. It has also been used by Brown et al. [21] to fit the impedance spectra of TiN or $\mathrm{ZrN}$ coatings produced on AISI 304 stainless steel in $0.5 \mathrm{M} \mathrm{NaCl}$. The equivalent circuit consists of the following elements: a cell resistance $R_{\Omega}$, a capacitance $C_{\mathrm{def}}$ and a charge transfer resistance $R_{\mathrm{def}}$ representing defects in the coatings, and a capacitance $C_{\mathrm{dl}}$ and a charge transfer resistance $R_{\mathrm{ct}}$ for the remainder of the coating layer regarded as intact-Fig. $7 \mathrm{~b}$ shows these two time constants. The charge transfer resistance of the intact coating layer is related to slow penetration of the electrolyte through the pores or pinholes existing in the coating [21,22]. This is in agreement with decreasing $R_{\mathrm{ct}}$ with immersion time. The capacitances were represented by constant phase elements (CPEs) in order to take into account the frequency dispersion normally found for solid electrodes. The values of $R_{\mathrm{ct}}$ and $C_{\mathrm{dl}}$, due to the semi-circle at lower frequencies, are given in Table 5. The substrate/coating systems presented $R_{\mathrm{ct}}$ values up to 7 times larger than those of the uncoated steel substrates [17].

The major differences between the impedance spectra are most clearly visible after $10 \mathrm{~min}$ immersion; after 1 and $4 \mathrm{~h}$ immersion differences are not significant except for those of coated as-received chromium steel, compare Fig. 6a-c. It can be inferred that after $10 \mathrm{~min}$ immersion the aggressive species had not yet reached the substrate by diffusion through the smaller defects or pores in the coatings, being indicative of a more compact structure. 


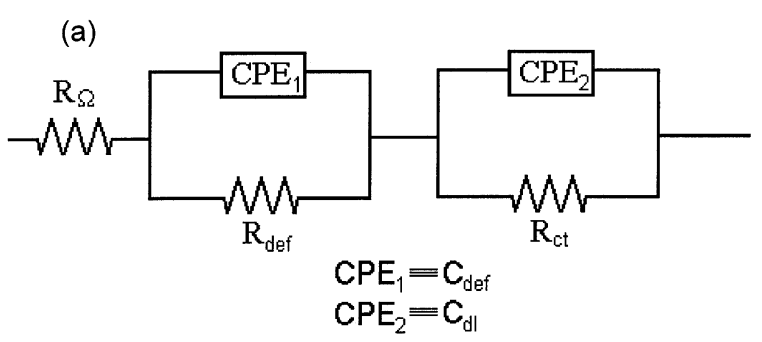

(b)

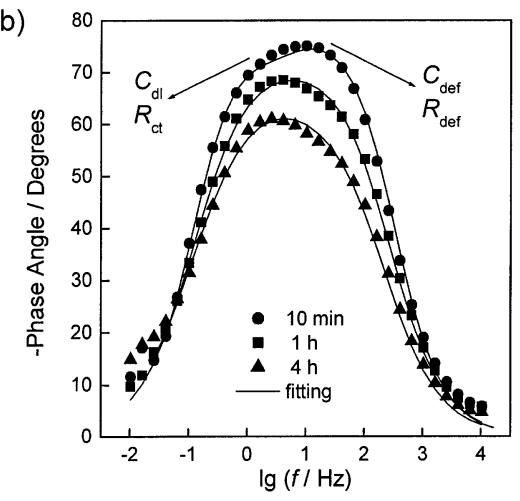

Fig. 7. (a) Equivalent circuit used to adjust the impedance spectra of the steel/WTiN coated systems in $0.1 \mathrm{M} \mathrm{KCl} . R_{\Omega}$, electrolyte resistance; $\mathrm{CPE}_{1}$ and $\mathrm{CPE}_{2}$, constant phase elements, used to represent the capacitance of the double layer and the capacitance of the coating defects; $R_{\mathrm{ct}}$, charge transfer resistance for the steel corrosion; $R_{\mathrm{def}}$, resistance of the coating defects; (b) Bode plots of chromium steel $\mathrm{AR}$ at different immersion times, evidencing the two time constants shown by the WTiN coated steels.

The system chromium steel as-received/coating showed the highest values of $R_{\mathrm{ct}}$, at all immersion times. Even after $1 \mathrm{~h}$ immersion, the $R_{\mathrm{ct}}$ value is significantly higher than that of the other systems, Fig. 6b. This supports the fact that this system has a more compact coating as the result of a better interaction between the substrate and the WTiN coating.

The HSS $\left(650{ }^{\circ} \mathrm{C}\right) /$ coating system presented the lowest $R_{\mathrm{ct}}$ value after $10 \mathrm{~min}$ immersion. This is in agreement with the results obtained by the other electrochemical techniques.

The capacitance increased with immersion time, which suggests an increase of the system surface area resulting from the localised attack by formation and growth of pits on the surface of the coating, as well as accumulation of corrosion products involved in the substrate oxidation process.

Two time constants were found, as in this work, from the impedance spectra of AISI 304 stainless steel coated with $\mathrm{TiN}$ or $\mathrm{ZrN}$ in $0.5 \mathrm{M} \mathrm{NaCl}$ [21]. However, unlike in this work, the system impedance at low frequency increased with immersion time. The reason for the difference is probably that there is no electrolyte pene- tration through to the substrate, although the stainless steel substrate itself is also much more inert.

\subsection{SEM and EDS analysis of the WTiN coated steels}

All samples of WTiN coated steels underwent localised corrosion with the formation of pits in the underlying substrate during the electrochemical experiments, as had been observed for the uncoated steels [15-17]. Fig. 8 shows micrographs of this localised corrosion of the coated systems. In all cases substrate corrosion leads to rupture of the WTiN coating, pieces of which often remain around the centre of the pits (Fig. 8b). At the end of the experiments the pit diameter was of the order of tens of micrometres. A detailed model of the corrosion mechanism of this type of coated steel can be found in Ref. [10].

EDS spectra obtained at different distances in the zone of the oxide circular ring surrounding the pit in Fig. 9a, for the HSS heat-treated at $550{ }^{\circ} \mathrm{C} / \mathrm{WTiN}$ system are shown in Fig. 9b. The spectra have main signals due to $\mathrm{Fe}$, probably related to corrosion products, and those of $\mathrm{W}$ and $\mathrm{Ti}$, related to the WTiN coating (Fig. 9b, point 1). At lesser distances from the pit centre (Fig. 9b, points 2 and 3), a signal due to $\mathrm{Cr}$ appears due to products of substrate corrosion, which becomes significant relative to those of $\mathrm{W}, \mathrm{Ti}$ and $\mathrm{Fe}$. The same behaviour was observed for WTiN coated chromium steels and for the other samples of HSS.

\subsection{Comparative remarks}

The results obtained show that the systems based on chromium steel substrate are the most resistant to corrosion. Regarding the variation of open circuit potential for these systems, Fig. 4b, the presence of either an almost time-invariant potential or potential transients in the positive direction can be observed, probably related to the passivation or repassivation/activation of pits, respectively. It can be deduced that the presence of sufficient $\mathrm{Cr}$ content in steels gives rise to its passivation (vide e.g. stainless steels). This behaviour, in comparison with the uncoated steel, suggests that enrichment of

Table 5

Electrochemical impedance parameters obtained through equivalent circuit fitting for the WTiN coated steels in $0.1 \mathrm{M} \mathrm{KCl}$ at open circuit potential after different immersion times

\begin{tabular}{|c|c|c|c|c|c|c|}
\hline \multirow{2}{*}{$\begin{array}{l}\text { Substrate for WtiN } \\
\text { coated system }\end{array}$} & \multicolumn{3}{|c|}{$R_{\mathrm{ct}} / \mathrm{k} \Omega \mathrm{cm}^{2}$} & \multicolumn{3}{|c|}{$C / \mu \mathrm{F} \mathrm{cm}^{-2}$} \\
\hline & $10 \min$ & $1 \mathrm{~h}$ & $4 \mathrm{~h}$ & $10 \mathrm{~min}$ & $1 \mathrm{~h}$ & $4 \mathrm{~h}$ \\
\hline Chromium steel AR & 14.9 & 7.79 & 3.87 & 85.8 & 162 & 354 \\
\hline Chromium steel $\left(450^{\circ} \mathrm{C}\right)$ & 10.5 & 5.27 & 3.25 & 85.1 & 299 & 808 \\
\hline HSS AR & 11.6 & 5.67 & 3.26 & 90.6 & 257 & 787 \\
\hline $\operatorname{HSS}\left(550{ }^{\circ} \mathrm{C}\right)$ & 11.6 & 5.70 & 3.69 & 81.1 & 156 & 354 \\
\hline $\operatorname{HSS}\left(650^{\circ} \mathrm{C}\right)$ & 8.24 & 5.39 & 3.45 & 78.6 & 178 & 604 \\
\hline
\end{tabular}


(a)

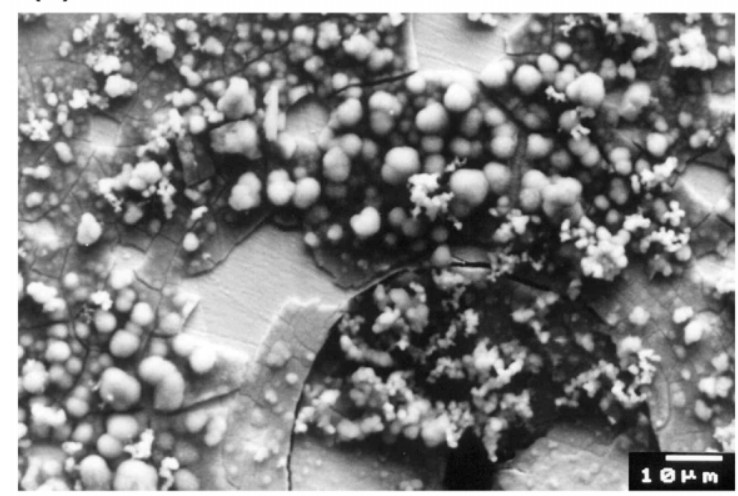

(b)

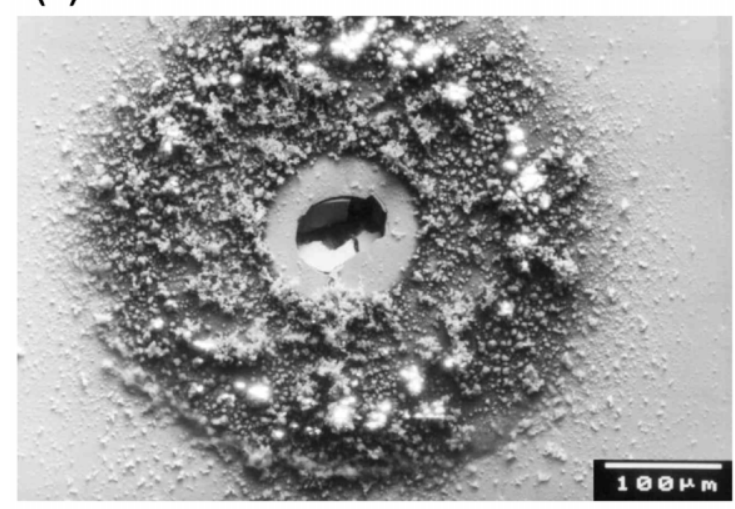

(c)

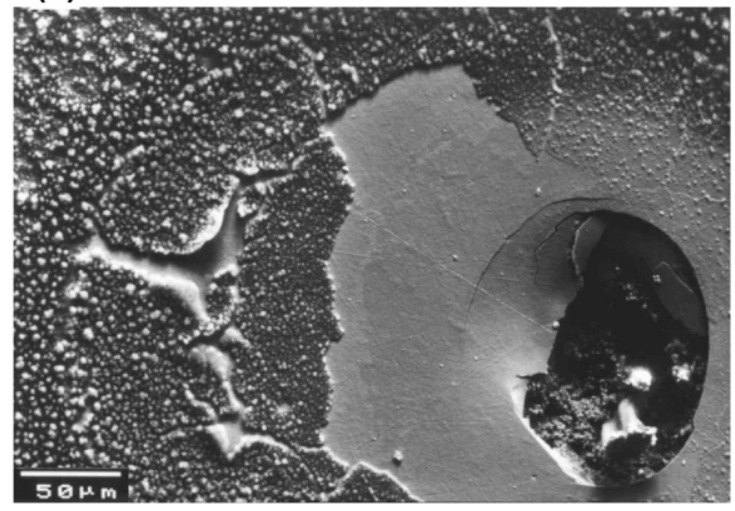

Fig. 8. Representative SEM micrographs showing the corrosion of WTiN coated steels in $0.1 \mathrm{M} \mathrm{KCl}$. (a) Details of an attacked area of WTiN coated carbon steel; (b) pit at the centre of a circular ring consisting of corrosion products in WTiN coated chromium steel AR; (c) pit in WTiN coated HSS $\left(650{ }^{\circ} \mathrm{C}\right)$ and the oxide layer that is formed around it.

chromium near the steel surface can arise during deposition. This could occur during the substrate cleaning procedure, when ion bombardment induces the preferential sputtering of some species leading to the enrichment in other elements, as can be the case for $\mathrm{Cr}$. On the other hand, as the deposition temperature is $450{ }^{\circ} \mathrm{C}$, the presence of nitrogen in the coating can act as a driving force for the migration of $\mathrm{Cr}$ towards the film/ substrate interface and formation of $\mathrm{CrN}$. The observation of a $\mathrm{Cr}$ signal in the pit mouth by EDS analysis
(Fig. 9), demonstrates local Cr enrichment at the film/ substrate interface during coating deposition. This also means that the bulk steel substrate becomes poorer in $\mathrm{Cr}$, causing initiation of localised corrosion.

Several publications have advanced the same hypothesis of chromium migration. For example, it was observed that $400{ }^{\circ} \mathrm{C}$, which is the critical nitriding temperature of stainless steel, corresponds to the threshold temperature of chromium diffusion activation [2325]. At higher temperatures, chromium in the surface atomic layers segregates towards the substrate surface and forms stable CrN [24,26]. During sputtering, samples reach temperatures higher than $400{ }^{\circ} \mathrm{C}$. Bellanger and Rameau [27] found that at elevated temperature during magnetron sputtering deposition of TiN on AISI 630 stainless steel, $\mathrm{Cr}$ and Mo can diffuse out of the steel to the interface and even into the deposit, with formation of $\mathrm{CrN}$, which improves the adhesion.

Regarding the variation of open circuit potential with time, this can be ascribed to electrolyte penetration through the coating. Besides evidence from previous work on WTiN films [10,11], this was also observed for AISI 4340 steel coated with $\mathrm{Ti}$ or $\mathrm{TiN}$ in a solution of $3 \% \mathrm{NaCl}$ [28], and was justified in terms of the presence of pores in the coating, permitting electrolyte penetration and thence corrosion of the steel substrate [29]. Similar conclusions were reached regarding TiN in $0.5 \mathrm{M} \mathrm{NaCl}$ [21]. Such a type of explanation can be applied to the WTiN coatings studied here, particularly in view of the link between a lower density of coating defects and higher corrosion resistance.

\section{Conclusions}

Coatings of WTiN, composition $31 \mathrm{~W}, 29 \mathrm{Ti}$ and 40 $\mathrm{N}$ at.\%, were deposited by sputtering on carbon steel, chromium steel and HSS, and the corrosion behaviour investigated in aqueous $0.1 \mathrm{M} \mathrm{KCl}$ solution by open circuit potential measurements, polarisation curves and electrochemical impedance spectroscopy, together with $\mathrm{X}$-ray diffraction and SEM with chemical microanalysis of the corroded and uncorroded coating/substrate systems. The effect of the steel heat treatment on the performance of the steel/WTiN system was also studied.

Coated steels present a higher corrosion resistance than the respective uncoated steels, evidencing the protective nature of the WTiN coatings, and there are differences according to the substrate.

The behaviour of each set of steel/WTiN coating system for different kinds of electrochemical measurement, did not always lead to exactly the same order of corrosion susceptibility. However, based on the overall behaviour, the following order of corrosion resistance can be established:

$$
\begin{aligned}
\text { Carbon Steel/WTiN } & <\text { HSS } / \text { WTiN } \\
& <\text { Chromium Steel/WTiN }
\end{aligned}
$$


(a)

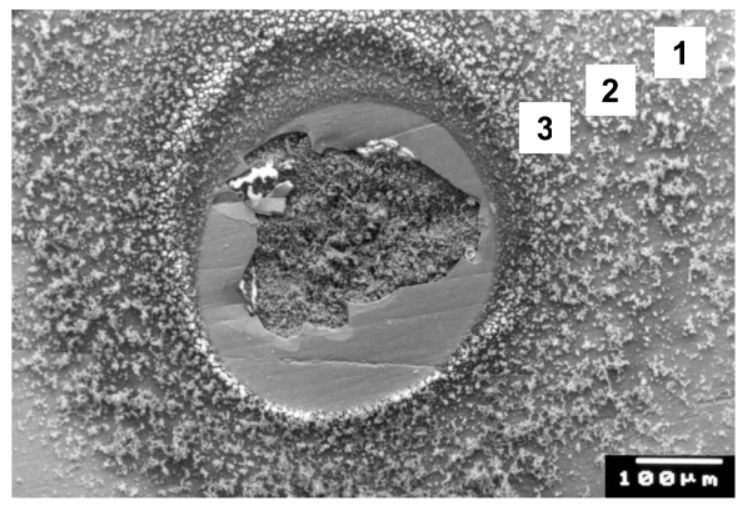

(b)
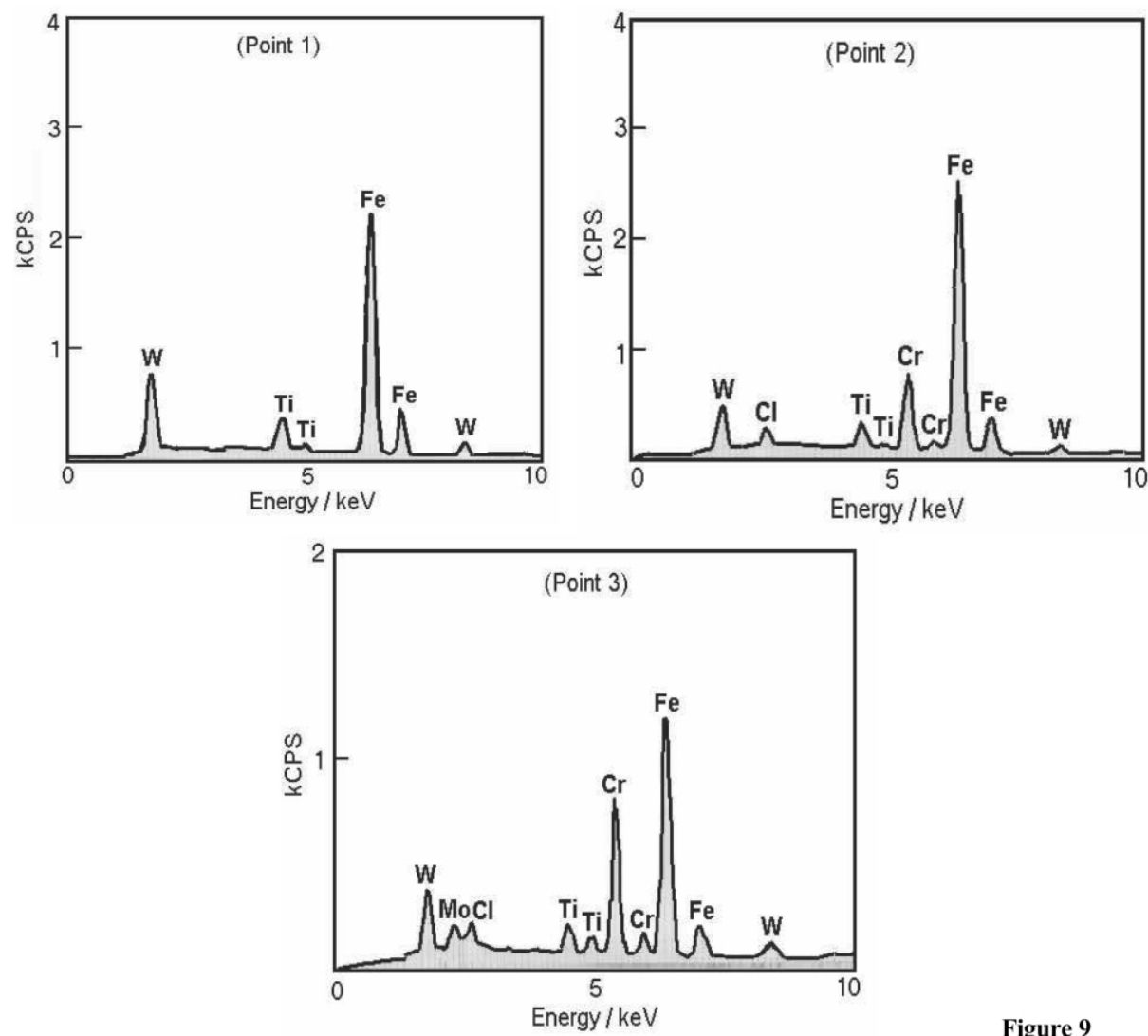

Figure 9

Fig. 9. (a) SEM micrograph of a pit in the WTiN coated HSS sample heat-treated at $550{ }^{\circ} \mathrm{C}$ and (b) EDS spectra obtained at points $1,2,3$ at the oxide circular ring surrounding the pit shown in the SEM micrograph.

The best corrosion resistance of the systems chromium steel/WTiN can be associated with a possible Cr diffusion from the steel matrix towards its surface during the coating deposition process, with consequent improvement of the corrosion performance.

Substrate heat treatment has some influence on the corrosion of the HSS/coating system. It is suggested that there may be one ideal steel treatment temperature at which the coating adhesion is higher, as evidenced by HSS tempered at $550{ }^{\circ} \mathrm{C}$ in this work.

It was demonstrated that the main cause of localised attack is penetration of electrolyte through the coating defects, reaching the substrate. This was clearly reflected in the worst performance of the carbon steel/WTiN system, the respective uncoated carbon steel also being the most susceptible to pitting corrosion.

\section{Acknowledgments}

V.A.A. thanks CNPq (Brazil), project 200396/99-4, for a post-doctoral fellowship. The authors thank ICEMS, Coimbra (research unit 103) for financial support. 


\section{References}

[1] J.S. Zabinski, A.A. Voevodin, J. Vac. Sci. Technol. A 16 (1998) 1890.

[2] B.F. Chen, W.L. Pan, G.P. Yu, J. Hwang, J.H. Huang, Surf. Coat. Technol. 111 (1999) 16.

[3] S. Rudenja, C. Leygraf, J. Pan, P. Kulu, E. Talimets, V. Mikli, Surf. Coat. Technol. 114 (1999) 129.

[4] M. Herranen, U. Wiklund, J.-O. Carlsson, D.S. Hogmark, Surf. Coat. Technol. 99 (1998) 191.

[5] J. Castanho, A. Cavaleiro, M.T. Vieira, Vacuum 45 (1994) 1051.

[6] C. Louro, A. Cavaleiro, Surf. Coat. Technol. 74-75 (1995) 998.

[7] C. Louro, A. Cavaleiro, J. Electrochem. Soc. 144 (1997) 259.

[8] C.M.A. Brett, A. Cavaleiro, Mater. Sci. Forum 192-194 (1995) 797.

[9] C.M.A. Brett, C.-M. Nimigean, Thin Solid Films 311 (1997) 1.

[10] C.M.A. Brett, A. Cavaleiro, Thin Solid Films 322 (1998) 263.

[11] J.C. Oliveira, A. Cavaleiro, C.M.A. Brett, Corros. Sci. 42 (2000) 1881.

[12] C.M.A. Brett, A. Cavaleiro, European Federation of Corrosion Publications, Number 28 (2000), Chapter 11, p. 155.

[13] S.-C. Lee, W.-Y. Ho, F.D. Lai, Mater. Chem. Phys. 43 (1996) 266.
[14] J. Munemasa, T. Kumakiri, Surf. Coat. Technol. 49 (1991) 496.

[15] C.M.A. Brett, P.I.C. Melo, J. Appl. Electrochem. 27 (1997) 959.

[16] V.A. Alves, C.M.A. Brett, A. Cavaleiro, J. Appl. Electrochem. $31(2001) 65$.

[17] V.A. Alves, C.M.A. Brett, A. Cavaleiro, Revista de Corrosão e Protecção de Materiais 20 (2001) 17.

[18] Joint Committee on Powder Diffraction Standards, Powder Diffraction File, International Center for Diffraction Data, Swarthmore, PA, Cards 25-1257 and 38-1420.

[19] G. Dirks, R.A.M. Wolters, A.E.M. De Veirman, Thin Solid Films 208 (1992) 181.

[20] J. Thornton, J. Vac. Sci. Technol. A 4 (1986) 3059.

[21] R. Brown, M.N. Alias, R. Fontana, Surf. Coat. Technol. 62 (1993) 467.

[22] R.M. Souto, H. Alanyali, Corros. Sci. 42 (2000) 2201.

[23] Z.L. Zhang, T. Bell, Surf. Eng. 1 (1985) 131.

[24] R. Wei, Surf. Coat. Technol. 83 (1996) 218.

[25] R. Wei, J.J. Vajo, L.N. Matossian, et al., Surf. Coat. Technol. 83 (1996) 235.

[26] K.-T. Rie, E. Menthe, A. Matthews, K. Legg, J. Chin, MRS Bull. 21 (1996) 46.

[27] G. Bellanger, J.J. Rameau, Electrochim. Acta 40 (1995) 2519.

[28] C.V. Franco, L.C. Fontana, D. Bechi, A.E. Martinelli, J.L.R. Muzart, Corros. Sci. 40 (1998) 103.

[29] L.A. Shalaby, Corros. Sci. 11 (1971) 767. 